\title{
Vitamin D Supplementation Does Not Improve the Severity or the Resolution of Ultraviolet B-Induced Acute Erythema
}

\author{
Florence Libon $^{\mathrm{a}}$ Laurence Seidel $^{\mathrm{b}}$ Etienne Cavalier ${ }^{\mathrm{c}}$ Arjen F. Nikkels ${ }^{\mathrm{a}}$ \\ Departments of a Dermatology, ${ }^{b}$ Bio-Statistics and ${ }^{c}$ Clinical Chemistry, CHU of Sart Tilman, University of Liège, Liège, Belgium
}

\section{Key Words}

Vitamin D · Photoprotection · Ultraviolet B-induced erythema. Skin cancer $\cdot$ Inflammation

\begin{abstract}
Background: Whether vitamin D supplementation alleviates the severity of ultraviolet B (UVB)-induced erythema and/or facilitates its resolution remains undetermined. $\mathbf{O b}$ jective: To study the effect of oral vitamin D on UVB-induced erythema and its resolution in fair-skinned subjects. Methods: UVB-induced erythema was quantified using a Chroma Meter ${ }^{\circledR}$ in 50 volunteers $48 \mathrm{~h}$ before and 10 days after the random administration of 200,000 IU vitamin $D(n=40)$ or placebo $(n=10)$. Resolution of erythema in both groups was assessed by chromametry 24,48 , and $72 \mathrm{~h}$ after vitamin D administration. Results: No statistical difference between erythema values before and after administration in the vitamin D-supplemented group ( $p=0.44)$ or the placebo group $(p=0.34)$ was noted. No statistical difference was evident between both groups with respect to resolution of erythema $(p=0.30)$. Conclusion: Oral vitamin D supplementation neither improves protection against UVB-induced erythema nor facilitates its resolution.

(c) 2015 S. Karger AG, Basel
\end{abstract}

\section{Introduction}

Sunburn is an ultraviolet B (UVB)-induced phenomenon and represents one of the initial cornerstones in the pathogenesis of malignant melanoma and nonmelanoma skin cancer [1,2]. Hence, photoprotection and sun avoidance are of capital importance in the fight against skin cancer. Patients who have had a melanoma, squamous cell carcinoma, or basal cell carcinoma are at risk of vitamin $\mathrm{D}$ deficiency due to the recommendation of sun avoidance, and vitamin D supplementation is common practice in this patient population. However, vitamin D should be given upstream since it could have a preventive role in carcinogenesis. Indeed, previous studies have found that vitamin D supplementation or higher vitamin D serum levels may be associated with a reduced incidence [3] or a better prognosis of skin cancer, respectively [4]. Moreover, solar radiation, via the vitamin D synthesized in the skin, may have a beneficial influence on both the incidence and the outcome of melanoma [5]. However, thorough epidemiologic evidence that adequate vitamin $\mathrm{D}$ supplementation or solar exposure protects against nonmelanoma skin cancer [6] and melanoma $[3,5,7]$ is lacking.

\section{KARGER 125}

(c) 2015 S. Karger AG, Base

$1018-8665 / 15 / 2313-0280 \$ 39.50 / 0$

E-Mail karger@karger.com

www.karger.com/drm
Prof. Dr. A.F. Nikkels, MD, PhD

Department of Dermatology

CHU of Sart Tilman, University of Liège

BE-4000 Liège (Belgium)

E-Mail af.nikkels@ chu.ulg.ac.be 
Table 1. Study flow chart

\begin{tabular}{lllllllll}
\hline Visit & \multicolumn{1}{l}{ Day } & & & & & & \\
\cline { 2 - 8 } & 1 & 2 & 4 & 14 & 15 & 16 & 17 \\
\hline Induction of UVB erythema & $\mathrm{X}$ & & & $\mathrm{X}$ & & & \\
Vitamin D serum status & $\mathrm{X}$ & & & $\mathrm{X}$ & & & \\
Colorimeter (a*-C) & & $\mathrm{X}$ & & & $\mathrm{X}$ & $\mathrm{X}$ & $\mathrm{X}$ \\
200,000 IU vitamin D or placebo & & & $\mathrm{X}$ & & & & \\
\hline
\end{tabular}

Vitamin D displays a high number of in vitro photoprotective properties. Calcitriol [1a,25-dihydroxyvitamin $\mathrm{D}_{3}$ or $1,25(\mathrm{OH})_{2} \mathrm{D}_{3}$ ] may enhance keratinocyte [8-13], melanocyte [13] and fibroblast $[10,13]$ survival after UVR exposure by reducing UV-induced promutagenic DNA damage like cyclobutane pyrimidine dimers [8-13], 8-oxo-7,8-dihydro-2-deoxyguanosine [9, 14], 3-nitrotyrosine, and 8-nitroguanosine $[9,15,16]$, which are mutagenic and are markers of inflammation and carcinogenesis. Moreover, $1,25(\mathrm{OH})_{2} \mathrm{D}_{3}$ could also influence the upregulation of p53, allowing improvement of DNA repair [13].

Whether these in vitro results on photoprotection are clinically relevant and whether eventual photoprotective effects are influenced by the vitamin D serum status remain undetermined.

This pilot study evaluated whether oral vitamin D supplementation in fair-skinned healthy individuals affects the severity of UVB-induced erythema and facilitates its resolution.

\section{Materials and Methods}

This pilot study was performed in accordance with the Helsinki Protocol (2000) and was approved by the University Hospital Ethics Committee. All study procedures were explained to the volunteers. All participants signed an informed consent form. The sequence of this study is presented in table 1.

\section{Patients}

Fifty phototype III [Fitzpatrick's classification type III: fair to matt skin, sometimes burns, always tans (medium tan), a few freckles] young healthy volunteers (males: $\mathrm{n}=21$, females: $\mathrm{n}=29$, mean age $22.3 \pm 1.9$ years, BMI $21.3 \pm 1.96$ ) were invited to participate in this study. They comprised a homogenous population in order to reduce the influence of some variables (BMI, age, and no vitamin D supplementation [17]) on vitamin D production. This study was performed in November to minimize natural UVB exposure. The exclusion criteria were as follows: oral vitamin D supplementation, age $<18$ or $>26$ years, BMI $<18$ or $>25$, a high dietary intake of vitamin D, pregnancy, lactation, skin disease, im- munosuppression, photosensitizing drug intake, photosensitizing disease, liver insufficiency, PUVA or UVB therapy, and recent holidays in the sun or sunbed less than 1 month prior to baseline use.

\section{UVB Erythema Induction}

A standardized UVB-induced erythema was induced on days 1 and 14 using the Gigatest ${ }^{\circledR}$ UVB-MED Tester UVB-311 (narrowband, 310-315 nm; Medisun ${ }^{\circledR}$, Brühl, Germany) (table 1). The Medisun Gigatest MED displays 5 test fields, each with a diameter of $15 \mathrm{~mm}$. The 5 dose levels vary from 100 to $13 \%$ and are obtained through special high-value coated filters. UVB-induced erythema is a recognized marker for cutaneous inflammation and it is a valuable tool as an indirect marker for increased skin cancer risk [7]. The UVB energy output in the $100 \%$ transmission field averages 4 $\mathrm{mW} / \mathrm{cm}^{2}$. The $100 \%$ transmission field was used for the colorimetric evaluation as this field was the only field visible with the naked eye in all of the patients on day 3. The Gigatest was applied vertically on each subject's right lower back using an irradiation time of $2.5 \mathrm{~min}$ for all subjects, equivalent to $0.6 \mathrm{~J} / \mathrm{cm}^{2}$, for $100 \%$ transmission. About $30 \mathrm{~min}$ after irradiation, patients were examined at the test site to exclude solar urticaria.

\section{Minimal Erythema Dose Evaluation}

A minimal erythema dose (MED) test was performed $24 \mathrm{~h}$ after Medisun Gigatest UVB exposure. The number of positive fields visible with the naked eye was evaluated over a total of 5 test fields.

\section{Chroma Meter ${ }^{\circledR}$ Erythema Evaluation}

Chroma Meter CR400 (Konica Minolta, Japan) evaluations of the $\mathrm{a}^{*}$ parameter according to the $\mathrm{L}^{*} \mathrm{a}^{*} \mathrm{~b}^{*}$ mode (CIE 1976, $+\mathrm{a} /-\mathrm{a}$ : red/green axis, +b/-b: yellow/blue axis, L: lightness) are a well-recognized and validated technique for measuring variations in UVBinduced erythema $[18,19]$. Measurements of the $a^{*}$ values of the UVB-induced erythemas were performed in triplicate. The perilesional skin served as a control (C) and its $\mathrm{a}^{*}$ value was measured in triplicate. To eliminate interobserver variation, all evaluations were performed by the same investigator under standardized illumination of the study room and positioning of the subject and investigator, as well as at a constant temperature. Chroma Meter measurements were performed on day 2 and on days 15, 16, and 17 (table 1). The difference in erythema intensity in interventional studies is a common measure to evaluate in vivo photoprotection [20].

\section{5(OH)D Analysis}

Blood samples were collected on days 1 and 14 (table 1). The samples were tested using a MassChrom ${ }^{\circledR} 25-\mathrm{OH}$-Vitamin $\mathrm{D}_{3} / \mathrm{D}_{2}$ LC-MS/MS kit with a 3-epi-25-OH-Vitamin $\mathrm{D}_{3}$ upgrade (LCMS; Gräfelfing, Germany) on the AB SCIEX QTRAP ${ }^{\circledR} 5500$ system (AB SCIEX; Framingham, Mass., USA). This LC-MS/MS is traceable to the National Institute of Standards and Technology (NIST) reference material SRM 2972 and the ID-LC-MS/MS 25(OH)D reference method procedure. The upgrade procedure allows $25(\mathrm{OH}) \mathrm{D}_{3}$ and $25(\mathrm{OH}) \mathrm{D}_{2}$ to be separated from their epimeric form 3-epi-25-(OH)-D. The coefficient of variation was $<2 \%$. All samples were measured in duplicate.

\section{Oral Vitamin D Supplementation}

Two oral doses of 100,000 IU equivalent to 200,000 IU of cholecalciferol $(n=40)$ and placebo $(n=10)$, identical in color and consistency, were simultaneously administered in liquid form at 




Fig. 1. Vitamin D serum levels of the placebo and vitamin D-supplemented groups on days 1 and 14 (individual values presented as means $\pm \mathrm{SE})$.

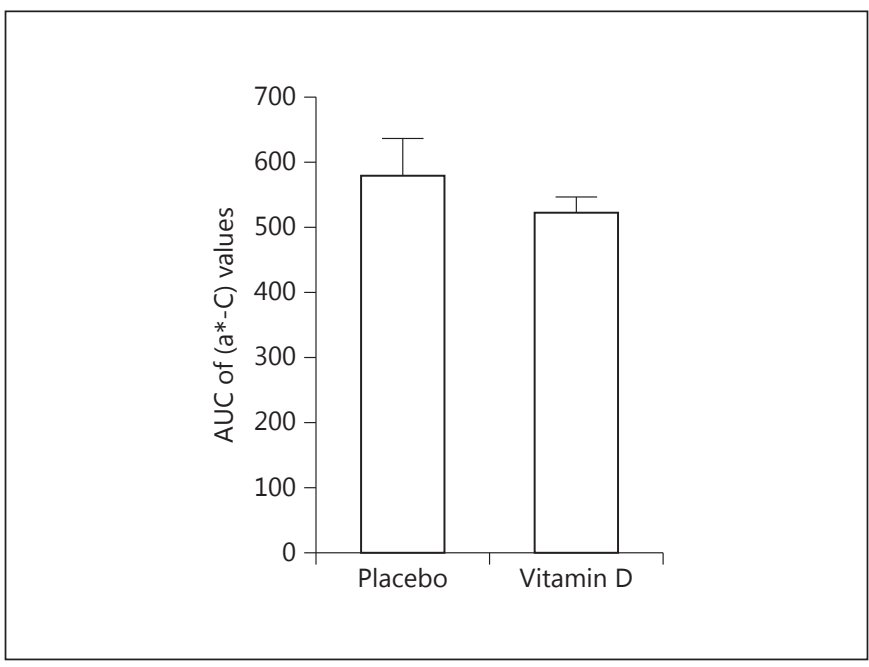

Fig. 2. AUC values of UVB-induced erythema in the placebo and vitamin $\mathrm{D}$-supplemented groups (mean $\pm \mathrm{SE}$; not statistically different). random to the volunteers on day 4 under the supervision of one of the investigators in a blinded manner. The dose of 200,000 IU of vitamin $\mathrm{D}$ and collection of blood sample 10 days after administration were chosen according to the results of oral vitamin D supplementation tests showing peak levels between 7 and 15 days [21].

\section{Endpoints}

The main outcomes were as follows: (1) mean increase in $25(\mathrm{OH}) \mathrm{D}$ after oral vitamin $\mathrm{D}$ supplementation $(\mathrm{n}=40)$ versus placebo $(n=10)$; (2) erythema intensity expressed as ( $\left.a^{*}-C\right)$ on day 15 versus $\left(a^{*}-\mathrm{C}\right)$ on day 2 in the placebo $(\mathrm{n}=10)$ and vitamin $\mathrm{D}$ supplemented group $(n=40)$, respectively; (3) alleviation of erythema expressed as the area under the curve (AUC), defined as the total $\left(\mathrm{a}^{*}-\mathrm{C}\right)$ values on days 15,16 , and 17 in the placebo $(\mathrm{n}=10)$ versus the vitamin D-supplemented group $(n=40)$; (4) photoprotection as assessed by the median number of visible test fields (24 $\mathrm{h}$ after Gigatest UVB testing) on day 15 versus day 2, and (5) erythema alleviation expressed as the mean number of visible test fields on days 15,16 , and 17 in the placebo group and the vitamin D-supplemented group.

\section{Statistical Analysis}

Data are expressed as means \pm SD. A paired Student $t$ test was used to compare increases in $25(\mathrm{OH}) \mathrm{D}$ after oral vitamin $\mathrm{D}$ supplementation and to compare the changes in $\left(\mathrm{a}^{*}-\mathrm{C}\right)$ on day 15 versus day 2 . The Student $t$ test was used to compare $\left(a^{*}-\mathrm{C}\right)$ and AUC values between the two groups.

$\mathrm{p}<0.05$ was considered statistically significant. Calculations were performed using SAS version 9.3 software (SAS Institute, Cary, N.C., USA) and figures 1-3 were drawn using S-PLUS version 8.1 software.

\section{Results}

There was no statistically significant difference in $25(\mathrm{OH}) \mathrm{D}$ levels before and after placebo administration in the control group (mean $27.3 \pm 11.5$ vs. $25.0 \pm 10.6 \mathrm{ng} /$ $\mathrm{ml}$, respectively, $\mathrm{p}=0.17$ ). A statistically significant increase was observed in the vitamin $\mathrm{D}$ supplementation group between days 1 and 14 (mean $24.6 \pm 9.4$ vs. $48.7 \pm$ $12.3 \mathrm{ng} / \mathrm{ml}$, respectively, $\mathrm{p}<0.0001)$. The increase in $25(\mathrm{OH}) \mathrm{D}$ levels differed significantly between the two groups ( $\mathrm{p}<0.0001$; fig. 1 ).

There was no statistically significant difference in the mean $\left(\mathrm{a}^{*} \mathrm{C}\right)$ values measured $24 \mathrm{~h}$ after UVB-induced erythema before and after vitamin $\mathrm{D}$ supplementation $(\mathrm{n}=40 ; 11.4 \pm 2.9$ on day 2 vs. $11.1 \pm 2.8$ on day $15, \mathrm{p}=$ $0.53)$, nor was there any statistically difference in the mean $\left(\mathrm{a}^{*}-\mathrm{C}\right)$ values measured $24 \mathrm{~h}$ after UVB-induced erythema before and after placebo administration $(\mathrm{n}=10$; mean $9.7 \pm 3.8$ on day 2 and $10.9 \pm 3.5$ on day $15, p=0.25$ ). There was no statistically significant difference between supplemented volunteers and placebo subjects with respect to erythema values $24 \mathrm{~h}$ after UVB erythema induction on day $15(\mathrm{p}=0.19)$.

The mean AUC values were $580 \pm 176$ in the placebo group and $524 \pm 147$ in the vitamin $\mathrm{D}$-supplemented group, but these were not statistically significantly different $(\mathrm{p}=0.30$; fig. 2$)$. The temporal evolution of $\left(\mathrm{a}^{*}-\mathrm{C}\right)$ values in the placebo and vitamin $\mathrm{D}$ groups is shown in 
Fig. 3. Temporal evolution of $\left(\mathrm{a}^{*}-\mathrm{C}\right)$ values in the placebo and vitamin $\mathrm{D}$ groups.

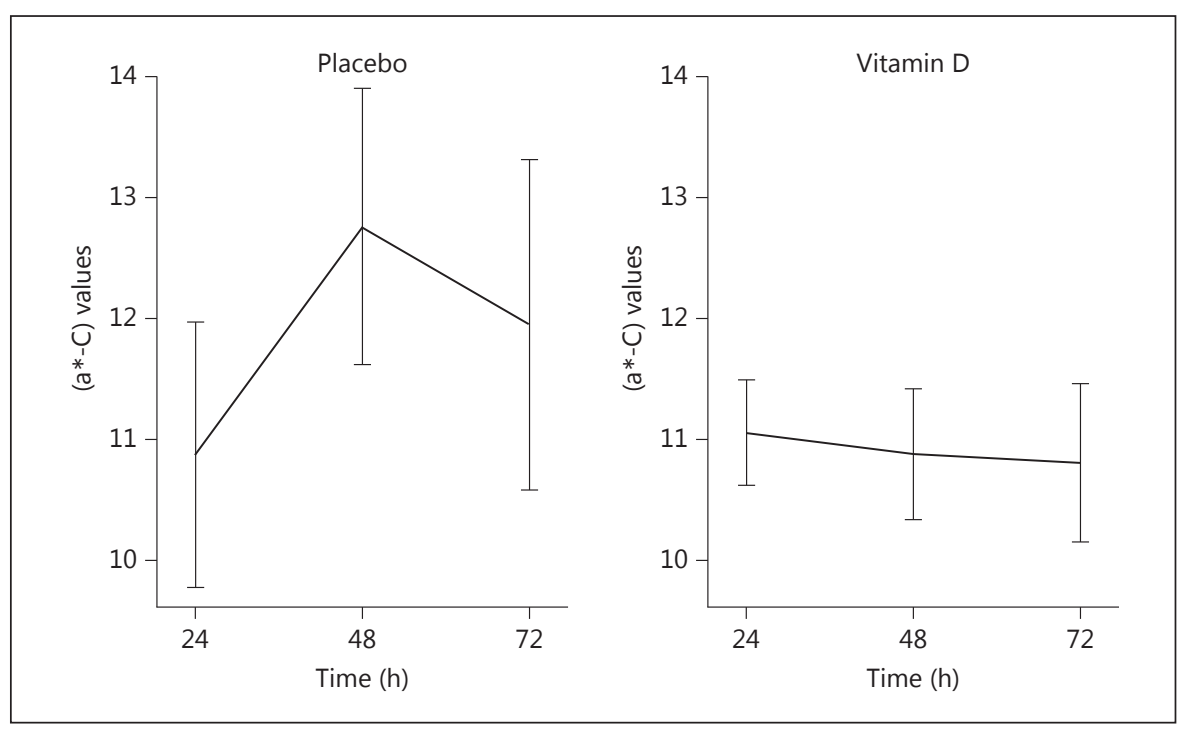

figure 3 (placebo mean at 24, 48, and $72 \mathrm{~h}$ : 10.88, 12.76, and 11.95 , respectively; vitamin D mean at 24,48 , and $72 \mathrm{~h}: 11.06,10.88$, and 10.81, respectively).

The median number of visible test fields at $24 \mathrm{~h}$ was 4 (minimum 1, maximum 4, mean 3.6; $\mathrm{n}=50$ ), which was equivalent to $0.195 \mathrm{~J} / \mathrm{cm}^{2}$, equivalent to the median MED. The mean number of visible test fields was 3.5 and 3.63 in the placebo and vitamin D-supplemented groups, respectively, on day 2 versus 3.6 in the placebo group on day 15 $(\mathrm{n}=10)$, and 3.83 in the vitamin $\mathrm{D}$-supplemented group $(\mathrm{n}=40)$. These differences were not statistically significant $(\mathrm{p}=0.59)$.

Erythema alleviation was also expressed as the mean number of visible test fields on days 15,16 , and 17 . The mean number of visible test fields in the placebo group was $3.6,3$, and 2.8 versus $3.83,3.5$, and 3 in the vitamin D-supplemented group on days 15,16 , and 17 , respectively. These differences were not statistically significant.

\section{Discussion}

The in vivo effects of vitamin $\mathrm{D}$ on the reduction of UVB-induced erythema remain unclear. Several studies have examined the clinical effect of topical calcitriol [22] or calcipotriol [23-26] on the MED in humans, and the results are contradictory. Calcipotriol is a synthetic derivative of calcitriol and it is known to display similar properties in terms of epidermal proliferation, modulation of keratinization, and inflammation [25]. The delay between topical application and UV irradiation varies among studies, potentially influencing the MED. In brief, calcipotriol $0.005 \%$ [23-27] applied 15-20 $\mathrm{min}[25,27]$ or immediately before $[23,24,26]$ irradiation, with a thick enough layer [23], influenced the MED [23-27], which could reach an increase of $31 \%$ [27] or an increase from 22.6 to $54.6 \mathrm{~mJ} / \mathrm{cm}^{2}$ [23]. Two hours after application, the MED returned to baseline [26]. In contrast, when calcitriol or calcipotriol was applied 24 [22], 12 [23], or $2 \mathrm{~h}$ before [24] or immediately after [22] irradiation, there was no influence on the UVB-induced erythema [22-24]. Nevertheless, when applied directly after UV exposure, it decreased the density of sunburn cells and the number of thymine dimers $[16,22]$. This suggests that the in vitro results do not necessarily correlate with an increase in MED [22].

Vitamin D also displays immunoregulatory properties. The immune effects of calcitriol on in vivo human skin are as yet unspecified [22]. Dietary vitamin D produced a reduction in DNA damage, in cutaneous inflammation, and in immunosuppression after UVB irradiation in a murine model [28]. This could mean that vitamin D counteracts the inhibitory effects of UVB on cutaneous immunity [29] and could be involved in immunomodulation [11]. Interestingly, in humans, UV-induced suppression of a delayed-type hypersensitivity reaction was measured after topical application of calcitriol but it failed to prevent UV-induced immunosuppression [22]. These controversial results can be explained by the differing immune properties of calcitriol in mice and humans and could be dose related, with protective immune effects appearing at higher concentrations (greater ab- 
sorption and greater dose relative to body weight in the mouse) [22]. The in vitro immunosuppressive properties of $1,25(\mathrm{OH})_{2} \mathrm{D}_{3}$ are dependent on genomic pathways and include, among others, inhibition of dendritic cell differentiation and maturation, inhibition of the production of numerous cytokines [30] or T cell proliferation [31] and polarization from a Th1 and Th17 phenotype towards a Th2 phenotype [32]. A recent analysis showed that vitamin $\mathrm{D}$ modulates tumor suppression via a mechanism that depends on the amount of vitamin $\mathrm{D}$ receptor in the skin [33].

This pilot study revealed that high-dose oral vitamin $\mathrm{D}$ supplementation does not have an impact on the severity of a fixed-dose UVB-induced erythema. The mean serum level of cholecalciferol achieved in our study reached $48.7 \pm 12.3 \mathrm{ng} / \mathrm{ml}$ but may, however, not have been enough to observe any photoprotective effects. Furthermore, there was no improvement or acceleration in the resolution of UVB-induced erythema in the supplemented group and no difference in visual MED in the vitamin $\mathrm{D}$ versus placebo groups. These results imply that oral vitamin $\mathrm{D}$ supplementation is probably of no use as protective oral therapy against sunburn or as a preventive technique to increase the healing speed of sunburn. It may be that any subtle antierythema effect of vitamin D is only observable at the threshold of erythema and not with supra-MED doses. Indeed, although the groups were all skin type III, they likely had a reasonable range of MED, and so using the highest dose in all participants may have resulted in missing some anti-inflammatory effects at the erythema threshold. Moreover, Chroma Meter measurements were not taken at each participant's MED site, but this was in order to still be able to have a measurable residual erythema on day 17 , equaling $72 \mathrm{~h}$ after induction. Interestingly, using a fluorescent lamp with an emission spectrum of $280-350 \mathrm{~nm}$ and a peak of $310-315 \mathrm{~nm}$, it has been observed that calcitriol [34] and calcipotriol [25] have photoprotective actions against UVB-induced reduction of the viability of cultured keratinocytes [34] or of DNA synthetic activity [25] in certain UVB dose ranges, but this was not observed beyond 50 $\mathrm{mJ} / \mathrm{cm}^{2}$ or $60 \mathrm{~mJ} / \mathrm{cm}^{2}$, respectively. This would imply that calcitriol and calcipotriol are photoprotective only at lower doses of UVB radiation. Thus, the importance of vitamin D for photoprotection should no be overlooked. In the skin, mechanisms of endogenous photoprotection following sun exposure include, among others, increased pigmentation via melanocytes and increased cornification of keratinocytes. It has been previously reported that calcitriol could enhance these processes [35]. Vitamin D can be converted to $1,25(\mathrm{OH})_{2} \mathrm{D}_{3}$ due to the presence of vitamin D-25 hydroxylase and $25(\mathrm{OH}) \mathrm{D}$-1 $\alpha$-hydroxylase in keratinocytes [7], though the process takes several hours. This suggests that formation of $1,25(\mathrm{OH})_{2} \mathrm{D}_{3}$ in the skin seems to protect against the next rather than the initial UV irradiation [12], implying that exogenous analogues of calcitriol could represent an added value in sunscreens [35].

In brief, oral vitamin $\mathrm{D}$ supplementation in fairskinned healthy individuals does not improve direct UVB-induced erythema, and secondly single, high-dose, oral supplementation does not reduce the severity of acute UVB-induced inflammation. Hence, oral vitamin D supplementation may not be useful in reducing UVBinduced sunburn but it should not be omitted in the global approach against vitamin D deficiency and skin cancer given its antiproliferative effects, prodifferentiation actions, and inhibitory effects on the migration, invasion, and metastasis of skin cancer $[7,36]$.

\section{Conclusion}

The results of this pilot evaluation suggest that oral, single, high-dose vitamin D supplementation does not improve protection against acute UVB-induced erythema or facilitate its resolution in fair-skinned subjects. The role of oral supplementation of vitamin D in the prevention of skin cancer merits further investigation in order to evaluate the clinical relevance of its beneficial photoprotective in vitro properties.

\section{Disclosure Statement}

The authors have no competing interests to declare.

\begin{tabular}{|c|c|}
\hline References & $\begin{array}{l}\text { Kanavy HE, Gerstenblith MR: Ultraviolet ra- } \\
\text { diation and melanoma. Semin Cutan Med } \\
\text { Surg 2011;30:222-228. } \\
2 \text { Bikle DD: Protective actions of vitamin D in } \\
\text { UVB induced skin cancer. Photochem Photo- } \\
\text { biol Sci 2012;11:1808-1816. } \\
3 \text { Tang JY, Fu T, Leblanc E, Manson JE, Feld- } \\
\text { man D, Linos E, Vitolins MZ, Zeitouni NC, } \\
\text { Larson J, Stefanick ML: Calcium plus vitamin } \\
\text { D supplementation and the risk of nonmela- } \\
\text { noma and melanoma skin cancer: post hoc } \\
\text { analyses of the Women's Health Initiative } \\
\text { randomized controlled trial. J Clin Oncol } \\
\text { 2011;29:3078-3084. }\end{array}$ \\
\hline
\end{tabular}

Libon/Seidel/Cavalier/Nikkels 
4 Newton-Bishop JA, Beswick S, RandersonMoor J, Chang YM, Affleck P, Elliott F, Chan M, Leake S, Karpavicius B, Haynes S, Kukalizch K, Whitaker L, Jackson S, Gerry E, Nolan C, Bertram C, Marsden J, Elder DE, Barrett $\mathrm{JH}$, Bishop DT: Serum 25-hydroxyvitamin $\mathrm{D}_{3}$ levels are associated with Breslow thickness at presentation and survival from melanoma. J Clin Oncol 2009;27:5439-5444.

5 Egan KM, Sosman JA, Blot WJ: Sunlight and reduced risk of cancer: is the real story vitamin D? J Natl Cancer Inst 2005;97:161-163.

6 Bikle DD, Jiang Y: The protective role of vitamin D signaling in non-melanoma skin cancer. Cancers (Basel) 2013;5:1426-1438.

7 Libon F, Cavalier E, Nikkels AF: Vitamin D and the skin. Rev Med Liege 2013;68:458464.

-8 Sequeira VB, Rybchyn MS, Gordon-Thomson C, Tongkao-on W, Mizwicki MT, Norman AW, Reeve VE, Halliday GM, Mason RS: Opening of chloride channels by $1 \alpha, 25$ dihydroxyvitamin $\mathrm{D}_{3}$ contributes to photoprotection against UVR-induced thymine dimers in keratinocytes. J Invest Dermatol 2013; 133:776-782.

9 Gupta R, Dixon KM, Deo SS, Holliday CJ, Slater M, Halliday GM, Reeve VE, Mason RS: Photoprotection by 1,25 dihydroxyvitamin $\mathrm{D}_{3}$ is associated with an increase in p53 and a decrease in nitric oxide products. J Invest Dermatol 2007;127:707-715.

-10 Wong G, Gupta R, Dixon KM, Deo SS, Choong SM, Halliday GM, Bishop JE, Ishizuka S, Norman AW, Posner GH, Mason RS: 1,25-Dihydroxyvitamin D and three low-calcemic analogs decrease UV-induced DNA damage via the rapid response pathway. J Steroid Biochem Mol Biol 2004;89-90:567-570.

11 De Haes P, Garmyn M, Degreef H, Vantieghem K, Bouillon R, Segaert S: 1,25-Dihydroxyvitamin $\mathrm{D}_{3}$ inhibits ultraviolet B-induced apoptosis, Jun kinase activation, and interleukin-6 production in primary human keratinocytes. J Cell Biochem 2003;89:663673.

12 Dixon KM, Deo SS, Norman AW, Bishop JE, Halliday GM, Reeve VE, Mason RS: In vivo relevance for photoprotection by the vitamin D rapid response pathway. J Steroid Biochem Mol Biol 2007;103:451-456.

13 Dixon KM, Deo SS, Wong G, Slater M, Norman AW, Bishop JE, Posner GH, Ishizuka S, Halliday GM, Reeve VE, Mason RS: Skin cancer prevention: a possible role of 1,25dihydroxyvitamin $\mathrm{D}_{3}$ and its analogs. J Steroid Biochem Mol Biol 2005;97:137-143.
14 Gordon-Thomson C, Gupta R, Tongkao-on W, Ryan A, Halliday GM, Mason RS: 1 1,25 dihydroxyvitamin $\mathrm{D}_{3}$ enhances cellular defences against $\mathrm{UV}$-induced oxidative and other forms of DNA damage in skin. Photochem Photobiol Sci 2012;11:1837-1847.

15 Dixon KM, Norman AW, Sequeira VB, Mohan R, Rybchyn MS, Reeve VE, Halliday GM, Mason RS: $1 \alpha, 25(\mathrm{OH})_{2}$-vitamin D and a nongenomic vitamin $\mathrm{D}$ analogue inhibit ultraviolet radiation-induced skin carcinogenesis. Cancer Prev Res (Phila) 2011;4:1485-1494.

16 Song EJ, Gordon-Thomson C, Cole L, Stern H, Halliday GM, Damian DL, Reeve VE, Mason RS: 1a,25-Dihydroxyvitamin $\mathrm{D}_{3}$ reduces several types of UV-induced DNA damage and contributes to photoprotection. J Steroid Biochem Mol Biol 2013;136:131-138.

17 Libon F, Cavalier E, Nikkels AF: Skin color is relevant to vitamin D synthesis. Dermatology 2013;227:250-254.

18 Park SB, Huh CH, Choe YB, Youn JI: Time course of ultraviolet-induced skin reactions evaluated by two different reflectance spectrophotometers: Derma spectrophotometer and Minolta spectrophotometer CM-2002. Photodermatol Photoimmunol Photomed 2002;18:23-28.

19 Andreassi L, Flori L: Practical applications of cutaneous colorimetry. Clin Dermatol 1995; 13:369-373.

20 Young AR, Boles J, Herzog B, Osterwalder U, Baschong W: A sunscreen's labeled sun protection factor may overestimate protection at temperate latitudes: a human in vivo study. J Invest Dermatol 2010;130:2457-2462.

21 Laurent T, Lukas P, Rousselle O, Ferrante N, Carisi I, Gadisseur R, Cavalier E: Short term effect of a single oral loading dose of 100,000 IU of cholecalciferol on circulating 25-hydroxyvitamin D and 1,25-dihydroxyvitamin $\mathrm{D}$, phosphocalcic metabolism biomarkers and bone turnover biomarkers in healthy adults. Osteoporos Int 2013;24:279.

22 Damian DL, Kim YJ, Dixon KM, Halliday GM, Javeri A, Mason RS: Topical calcitriol protects from UV-induced genetic damage but suppresses cutaneous immunity in humans. Exp Dermatol 2010;19:e23-e30.

23 Lebwohl M, Hecker D, Martinez J, Sapadin A, Patel B: Interactions between calcipotriene and ultraviolet light. J Am Acad Dermatol 1997;37:93-95.
24 De Rie MA, Di Nuzzo S, Brands S, Hansen $\mathrm{AB}$, Bos JD: Calcipotriol ointment and cream or their vehicles applied immediately before irradiation inhibit ultraviolet B-induced erythema. Br J Dermatol 2000;142:1160-1165.

25 Youn JI, Park BS, Chung JH, Lee JH: Photoprotective effect of calcipotriol upon skin photoreaction to UVA and UVB. Photodermatol Photoimmunol Photomed 1997;13: 109-114.

26 Marisco RE, Dijkstra JW: UVB blocking effect of calcipotriene ointment $0.005 \%$. J Am Acad Dermatol 1996;34:539-540.

27 Maier H, Donath P, Ceovic R, Hoenigsmann H: UV extinction of $0.005 \%$ calcipotriol ointment. Br J Dermatol 1996;135:836.

28 Malley RC, Muller HK, Norval M, Woods GM: Dietary vitamin $D$ alters the response of the skin to UVB-irradiation depending on the genetic background of the mice. Photochem Photobiol Sci 2013;12:536-545.

29 Kuritzky LA, Finlay-Jones JJ, Hart PH: The controversial role of vitamin $\mathrm{D}$ in the skin: immunosuppression versus photoprotection. Clin Exp Dermatol 2008;33:167-170.

30 Berer A, Stöckl J, Majdic O, Wagner T, Kollars M, Lechner K, Geissler K, Oehler L: 1,25-Dihydroxyvitamin $\mathrm{D}(3)$ inhibits dendritic cell differentiation and maturation in vitro. Exp Hematol 2000;28:575-583.

- 31 Boonstra A, Barrat FJ, Crain C, Heath VL, Savelkoul HF, O'Garra A: 1alpha,25-Dihydroxyvitamin $\mathrm{D}_{3}$ has a direct effect on naive CD4(+) T cells to enhance the development of Th2 cells. J Immunol 2001;167:4974-4980.

-32 Baeke F, Takiishi T, Korf H, Gysemans C, Mathieu C: Vitamin D: modulator of the immune system. Curr Opin Pharmacol 2010;10: 482-484.

33 Bikle DD: The vitamin D receptor: a tumor suppressor in skin. Adv Exp Med Biol 2014; 810:282-302.

34 Lee J, Youn JI: The photoprotective effect of 1,25-dihydroxyvitamin $\mathrm{D}_{3}$ on ultraviolet light B-induced damage in keratinocyte and its mechanism of action. J Dermatol Sci 1998;18: 11-18.

35 Mason RS, Sequeira VB, Dixon KM, GordonThomson C, Pobre K, Dilley A, Mizwicki MT, Norman AW, Feldman D, Halliday GM, Reeve VE: Photoprotection by 1alpha,25-dihydroxyvitamin D and analogs: further studies on mechanisms and implications for UVdamage. J Steroid Biochem Mol Biol 2010;12: 164-168.

-36 Tang JY, Fu T, Lau C, Oh DH, Bikle DD, Asgari MM: Vitamin D in cutaneous carcinogenesis. Part 2. J Am Acad Dermatol 2012;67: 817.e1-e11. 